\title{
Investigação das propriedades físicas e mecânicas do concreto convencional com substituição parcial da areia pelas fibras de bambu
}

\author{
Investigation of the physical and mechanical properties of conventional concrete with partial \\ replacement of sand by bamboo fibers \\ Investigación de las propiedades físicas y mecánicas del hormigón convencional con reemplazo \\ parcial de arena fibras de bambú
}

\begin{abstract}
Resumo
As fibras naturais do bambu são de grande interesse como reforço de compósitos poliméricos, adicionadas em pequenas proporções à massa de concreto, tem por objetivo aumentar à resistência a compressão e melhorar seu desempenho estrutural e outro fator de grande importância na sua utilização é o aumento da resistência à tração fazendo que haja um controle na propagação de fissuras. O presente trabalho tem por objetivo avaliar a influência da substituição da areia pela de fibras de bambu nas propriedades físicas e mecânicas do concreto convencional. Pesquisas realizadas mostram que houve um aumento no interesse em utilizar compósitos naturais para o reforço do concreto, dentre eles a fibra do bambu. As fibras de bambu por apresentar propriedades mecânicas relevantes, baixa densidade, serem biodegradáveis e encontradas na natureza em abundância, mostram-se satisfatória e um ótimo compósito a ser adicionado na confecção de concretos. Os materiais utilizados foram caracterizados para elaboração do traço do concreto de referência calculado pelo método $\mathrm{ABCP}$ - ACI e confeccionados concretos com substituição de $2 \%$ e $5 \%$ de fibras de bambu em sua composição. Os concretos foram ensaiados quanto à resistência a compressão, módulo de elasticidade e resistência a tração direta nas idades de 14 e 28 dias. Os resultados mostram que a resistência à compressão axial não obteve uma alteração significativa, conforme foram adicionas as porcentagens de fibras de bambu em sua composição, apesar que o compósito atende a resistência mínima de $20 \mathrm{MPa}$ estabelecida pela NBR 6118 (2014), podendo ser usado para fins estruturais.
\end{abstract}

Palavras-chave: Concreto; Fibras de bambu; Resistência a compressão; Módulo de elasticidade. 


\begin{abstract}
The natural fibers of bamboo are of great interest as reinforcement of polymeric composites, added in small proportions to the concrete mass, aims to increase the compressive strength and improve its structural performance and the turn factor of great importance in its use is the increase of tensile strength making there a control in the propagation of cracks. The present work aims to evaluate the influence of sand substitution by bamboo fibers on the physical and mechanical properties of conventional concrete. Research shows that there was an increase in interest in using natural composites for the reinforcement of concrete, including bamboo fiber. Bamboo fibers because they have relevant mechanical properties, low density, biodegradable and found in nature in abundance, are satisfactory and a great composite to be added in the manufacture of concrete. The materials used were characterized to elaborate the trace of the reference concrete calculated by the ABCP - ACI method and made concrete with the addition of $2 \%$ and $5 \%$ of bamboo fibers in its composition. The concretes were tested for compressive strength, modulus of elasticity and direct tensile strength at the ages of 14 and 28 days. The results show that the axial compressive strength did not obtain a significant change, as the percentages of bamboo fibers were added in its composition, although the composite meets the minimum resistance of $20 \mathrm{MPa}$ established by NBR 6118 (2014), and can be used for structural purposes.
\end{abstract}

Keywords: Concrete; Bamboo fibers; Compressive strength; Modulus of elasticity.

\title{
Resumen
}

Las fibras naturales de bambú son de gran interés ya que el refuerzo de compuestos poliméricos, añadido en pequeñas proporciones a la masa de hormigón, tiene como objetivo aumentar la resistencia a la compresión y mejorar su rendimiento estructural y el factor otro de gran importancia en su uso es el aumento de la resistencia a la tracción haciendo allí un control en la propagación de grietas. El presente trabajo tiene como objetivo evaluar la influencia de la sustitución de arena por fibras de bambú en las propiedades físicas y mecánicas del hormigón convencional. La investigación muestra que hubo un aumento en el interés en el uso de compuestos naturales para el refuerzo del hormigón, incluida la fibra de bambú. Las fibras de bambú debido a que tienen propiedades mecánicas relevantes, de baja densidad, biodegradables y se encuentran en la naturaleza en abundancia, son satisfactorias y un gran compuesto para ser agregado en la fabricación de concreto. Los materiales utilizados se caracterizaron para elaborar la traza del hormigón de referencia calculado por el método ABCP - ACI y se hizo hormigón con la adición de $2 \%$ y $5 \%$ de fibras de bambú en su composición. Los hormigones se probaron para la resistencia a la compresión, el módulo de elasticidad y la resistencia a la tracción directa a las edades de 14 y 28 días. Los resultados muestran que la resistencia a la compresión axial no obtuvo un cambio significativo, ya que se agregaron los porcentajes de fibras de bambú en su composición, aunque el compuesto cumple con la resistencia mínima de 20 MPa establecida por NBR 6118 (2014), y puede ser utilizado con fines estructurales.

Palabras clave: Hormigón; Fibras de bambú; Fuerza compresiva; Módulo de elasticidad.

\section{Introdução}

O bambu desde os primórdios vem sendo utilizado de diversas formas, seja suas raízes para alimento, ou sua estrutura para confecção de casas, artesanatos e afins. Planta da família das gramíneas mostra-se desenvolto e tão resistente quanto à madeira e o aço. Encontrado em grande quantidade e variedade em regiões temperadas é pouco exigente quanto ao solo e ao clima, fazendo com que suas florestas correspondam a 3\% de todas as florestas do planeta (Santi, 2015).

Considerado como um material sustentável na construção civil possui baixo impacto gerado em seu cultivo e é também o recurso natural que se renova mais rapidamente, podendo levar de três a seis anos para se desenvolver por completo. Por sequestrar altas taxas de carbono da atmosfera se torna um grande contribuinte do meio ambiente (Farias, Silva \& Langer, 2007).

Devido a sua estrutura ser esbelta e longilínea e possuir grande quantidade de fibras biodegradáveis, renováveis, menos abrasivas e de baixa densidade aparente, a investigação das propriedades da substituição da areia com a fibra de bambu no concreto convencional tornam-se um grande atrativo para pesquisadores e engenheiros (Guimarães, Novack, Botaro, De Paula Protásio \& Couto, 2013).

Além disso, as fibras naturais do bambu também são de grande interesse como reforço de compósitos poliméricos, adicionadas em pequenas proporções à massa do concreto, tem por finalidade aumentar à resistência a compressão e melhorar seu desempenho estrutural. Outro fator de grande importância na sua utilização é o aumento da resistência à tração fazendo que haja um controle na propagação de fissuras (Mota, 2007). 
Paula e Nogueira (2021) investigaram três traços para o concreto convencional, com substituição de 1\% de fibra de bambu e $2 \%$ de fibra de bambu, onde foram submetidos os corpos-de-prova aos testes de compressão uniaxial e resistência à tração diametral nos dias 7, 14 e 28 dias da cura do concreto. Os resultados mostraram um aumento na resistência à tração de concreto com substituição de fibra de bambu em relação ao concreto convencional, em todos os dias em que os testes foram realizados, mas houve pouca diferença entre os traços de concreto convencional, com $1 \%$ e $2 \%$ de fibra em relação à resistência à compressão

Segundo Kumarasamy et al. (2020), com as variações na porcentagem do teor de fibras do concreto. É detectado que com a substituição de fibra no concreto, a resistência à compressão aumentou até $2 \%$ com a substituição de fibra. $\mathrm{O}$ acúmulo de fibra com o concreto em, $1 \%, 1,5 \%$ e $2 \%$ e $5 \%$ acarretam correspondentemente os valores da resistência à compressão do concreto em $0,9 \%, 1,38 \%, 1,73 \%$ e $1,98 \%$. Com a substituição de $2,5 \%$ de fibra no concreto, a resistência à compressão começou a diminuir em $0,34 \%$.

Segundo Marrero et al. (2017), a substituição das fibras de bambu ao concreto produziu maiores resistências à compressão e à tração dividida em misturas de concreto. Os dados mostram um incremento de $22 \%$ em resistência à compressão média e uma média de $17 \%$ da resistência à tracção. Este aumento é atribuído às fibras, o que dificulta a propagação de trincas na matriz de cimento endurecido. Esses efeitos positivos do fibras de bambu são mais manifestas em misturas com propriedades mecânicas. Este manuscrito através de estudos bibliográficos, normas e ensaios laboratoriais, busca investigar as propriedades físicas e mecânicas da substituição parcial da areia pela fibra de bambu no concreto convencional.

\section{Metodologia}

A areia tipo média foi utilizada como agregado miúdo e brita 1 como agregado graúdo, ambos provenientes da região de Itajubá, Minas Gerais. O cimento utilizado foi o CP-II-E-32 da fabricante Tupi e o bambu é da espécie Bambusa vulgaris Schrad (bambu verde), também encontrado em Itajubá-MG. Os materiais utilizados foram caracterizados quanto às características necessárias, para posterior determinação do traço do concreto pelo método ABCP/ACI.

A determinação da massa específica do agregado miúdo foi realizada segundo os procedimentos da norma ABNT NBR 16916 (2021) e da massa unitária compactada do agregado graúdo foi realizada de acordo com os procedimentos descritos na norma ABNT NBR 16972 (2021) e a determinação da massa específica do cimento Portland segundo os procedimentos da norma ABNT NBR 16605 (2017) e do agregado graúdo segundo os procedimentos da ABNT NBR 16917 (2021).

Para a determinação da composição granulométrica dos agregados (graúdo e miúdo), o procedimento descrito utilizado foi de acordo com a norma NBR NM 248 (2003) e para a determinação da massa específica do bambu para a espécie Bambusa Vulgaris, os valores de massa específica em todas as alturas são crescentes das camadas internas para as externas dos colmos do bambu, obtendo variações de 0,43 a $0,76 \mathrm{~g} / \mathrm{cm}^{3}$. Nisso, será adotado assim, uma massa específica de $0,76 \mathrm{~g} / \mathrm{cm}^{3}$, pois este é o maior valor de variação.

Realizada a etapa de caracterização dos materiais quanto as características necessárias para o cálculo do traço, procedeu-se ao cálculo pelo método ABCP-ACI.

Este método de dosagem experimental é baseado no método desenvolvido pela American Concrete Institute (ACI) e adaptado pela Associação Brasileira de Cimento Portland (ABCP), às condições brasileiras. Após a caracterização dos agregados e do resíduo, primeiramente estipulou-se a resistência característica do concreto em Fck $=25 \mathrm{MPa}$, e utilizou-se o desvio padrão de 4,0; obtendo-se assim, uma resistência de dosagem Fcj =32 MPa para a resistência média do concreto à compressão aos 28 dias. Utilizando-se a curva de Abrams, estabeleceu-se a relação água/cimento em 0,50; chegando assim ao consumo de materiais necessários para a produção de $1 \mathrm{~m}^{3}$ de concreto (sem substituição de fibras de bambu) sendo que a 
apresentação do traço ficou da seguinte forma: 1: 1,57: 2,62: 0,50. Sendo respectivamente as proporções de cimento; areia; brita e fator água/cimento.

Para a moldagem dos corpos de prova foi utilizado o agregado miúdo proveniente da areia natural classificada como areia média e para o agregado graúdo utilizou-se a brita 1 com dimensão máxima característica de $19 \mathrm{~mm}$, por ser uma granulometria utilizada nos canteiros de obras da região. Na produção do concreto foi utilizada uma betoneira de eixo inclinado com capacidade de 55 litros e a colocação dos materiais na betoneira seguiu a seguinte ordem: agregado graúdo, água, cimento, areia e fibra de bambu.

Os concretos com 3 composições diferentes foram preparados e submetidos à compressão axial nas idades de 14 e 28 dias, bem como, aos ensaios para determinação da massa específica. Para o cálculo da quantidade de materiais para cada concreto, foi determinado o volume de concreto para um corpo de prova, pela equação do volume de um cilindro.

O primeiro concreto, o concreto de referência, composto pelos elementos tradicionais do concreto que são cimento, água, areia e brita nas proporções correspondentes às do traço calculado. Dois concretos foram confeccionados com sua composição de areia alterada, sendo substituída nas proporções de $2 \%$ e $5 \%$ em relação ao volume da fibra de bambu.

Após a execução de cada mistura de concreto realizou-se o ensaio para a determinação da consistência do concreto pelo abatimento do tronco de cone (Slump test), conforme ABNT NBR 16889 (2020). Os valores da tolerância foram identificados segundo a ABNT NBR 7212 (2021). De acordo com a disponibilidade de equipamentos do laboratório, foi selecionado o uso de corpos cilíndricos de diâmetro de $15 \mathrm{~cm}$ e altura de $30 \mathrm{~cm}$ para a moldagem dos concretos de acordo com a norma ABNT NBR 5738 (2016).

Adotou-se a moldagem de 4 corpos de provas para cada idade dos concretos que seriam comprimidos para o ensaio de resistência a compressão e 3 corpos de provas para cada concreto para os demais ensaios. Após vinte e quatro horas foram desenformados e armazenados em câmara úmida para processo de cura por 28 dias. Em seguida, os corpos de prova cilíndricos, foram capeados na base e no topo com mistura de enxofre.

Para o ensaio de resistência a compressão foram moldados utilizando os procedimentos da NBR 5739 (2018) e a massa específica do concreto foi realizado segundo os procedimentos descritos na ABNT NBR 9778 (2009).

Para o ensaio do modulo de elasticidade foram moldados 3 corpos de prova para o traço, utilizando os procedimentos conforme a ABNT NBR 6118 (2014) e ABNT NBR 8522 (2021). Segundo a ABNT NBR 8522 (2021), o módulo de deformação estático para um material sob compressão axial simples é determinado a partir da declividade da curva tensãodeformação em corpos de prova cilíndricos sob carregamento uniaxial. O corpo de prova é submetido a cargas crescentes e a cada incremento de carga mede-se a deformação correspondente.

Para execução do ensaio a tração direta, as duas extremidades das amostras são mantidas fixas, na qual todas as peças que fornecem o sistema de rótulas são rosqueadas o suficiente para impedir qualquer rotação. O sistema é considerado único e firme, no entanto deve-se tomar cuidado com a manutenção do alinhamento da amostra na montagem inicial do ensaio de maneira a evitar qualquer excentricidade. Este procedimento favorece a indução de esforço somente de tração direta durante o carregamento, principalmente no ramo pós-fissuração dos compósitos reforçados com fibras.

\section{Resultados e Discussão}

Na Figura 1 são mostrados os resultados encontrados nos ensaios de consistência do concreto. Através dos resultados observou-se que não houve alteração na trabalhabilidade do concreto com $2 \%$ e $5 \%$ em relação ao concreto referência.

Segundo Dewi, Wijaya e Remayanti (2017), o aumento da concentração de resíduo da fibra de bambu pode diminuir a trabalhabilidade e qualidade do concreto. Independentemente do tipo de fibra, a perda da trabalhabilidade é proporcional à concentração de volume de fibras no concreto. Esta redução é influenciada pelo fator de forma da fibra, pela geometria da 
fibra, pela fração volumétrica adicionada, pelo traço do concreto e pela aderência das fibras com a matriz. Normalmente fibras longas e fibras com maior relação de aspecto tendem a reduzir mais a trabalhabilidade (Gói, 2010).

Figura 1. Abatimento do tronco de cone do concreto (Slump do concreto).

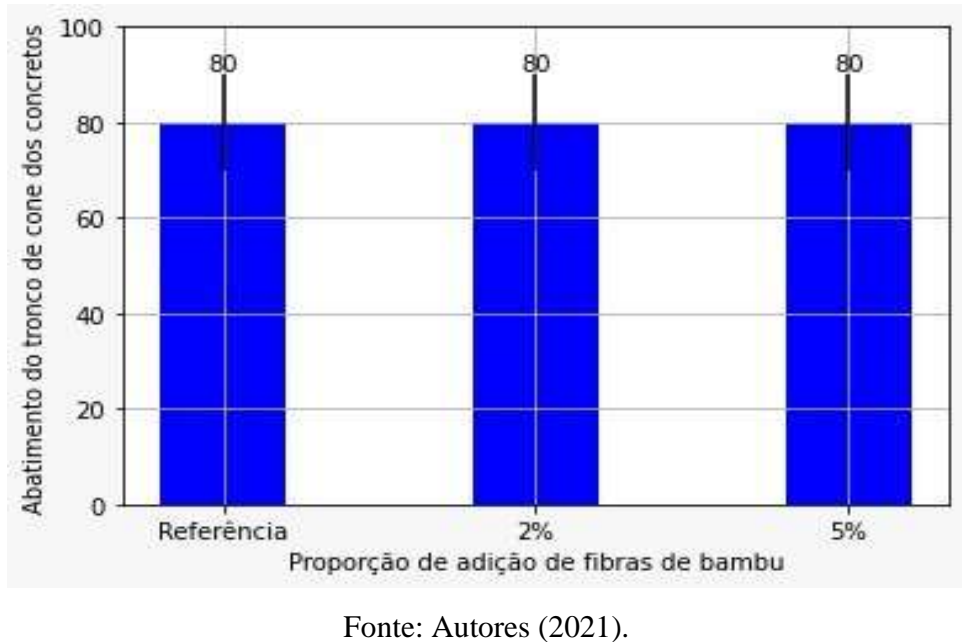

Monteiro e Mehta (2006) afirmam que "a substituição de fibras no concreto convencional, diminui consideravelmente a trabalhabilidade, que dependerá proporcionalmente do volume de fibras adicionado à mistura. Primeiramente, é difícil dispersar no concreto normal um grande volume de fibras, devido ao agrupamento de fibras e consequente formação de novelos. Adicionalmente, tanto o processo de vibração interna quanto a externa dos concretos com fibras podem influenciar a qualidade do produto final no estado endurecido. A vibração interna não é recomendada porque esse método de consolidação produz alinhamento preferencial e distribuição não uniforme das fibras.

A vibração externa também pode conduzir a uma orientação preferencial das fibras. Se o tempo de vibração utilizado no processo de consolidação for muito curto, apenas um pequeno alinhamento é observado. No entanto, para misturas que necessitem de um maior tempo de vibração para que ocorra uma boa consolidação, uma forte orientação das fibras pode ser observada" (Gói, 2010, p. 115) .

No Quadro 1 são mostrados os valores da composição granulométrica do agregado miúdo. Para o diâmetro máximo (DM), o valor encontrado para a areia é de $2,38 \mathrm{~mm}$; sendo classificados como agregado miúdo, pois seu diâmetro está situado entre $0,075 \mathrm{~mm}$ e $4,8 \mathrm{~mm}$. O valor do módulo de finura (MF) para os agregados miúdo foi de 2,81; respectivamente para a areia sendo classificada como média, pois o módulo de finura está entre 2,4 e 3,2. Os resultados demonstram que há uma maior quantidade, em porcentagem, ou seja, de massa retida de grãos de agregado miúdo foi de $0,30 \mathrm{~mm}$. 
Quadro 1. Granulometria da areia.

\begin{tabular}{|c|c|c|c|}
\hline $\begin{array}{c}\text { Peneira } \\
(\mathrm{mm})\end{array}$ & $\begin{array}{c}\text { Massa } \\
\text { Retida }(\mathrm{g})\end{array}$ & $\begin{array}{c}\text { Porcentagem } \\
\text { Retida }\end{array}$ & $\begin{array}{c}\text { Porcentagem } \\
\text { Retida Acumulada }\end{array}$ \\
\hline 4,76 & 1,12 & $0,30 \%$ & $0,30 \%$ \\
\hline 2,38 & 6,62 & $1,80 \%$ & $2,10 \%$ \\
\hline 1,19 & 15,45 & $4,19 \%$ & $6,29 \%$ \\
\hline 0,59 & 62,83 & $17,05 \%$ & $23,34 \%$ \\
\hline 0,297 & 126,90 & $34,45 \%$ & $91,60 \%$ \\
\hline 0,149 & 124,53 & $33,81 \%$ & $98,03 \%$ \\
\hline 0,074 & 23,71 & $6,44 \%$ & \\
\hline Total & 368,37 & $100,00 \%$ & \\
\hline Diâmetro Máximo (mm) & & 2,38 & \\
\hline Módulo de Finura & & 2,81 & \\
\hline Massa Específica (g/cm $\left.{ }^{3}\right)$ & & 2,33 & \\
\hline
\end{tabular}

Fonte: Autores (2021).

No Quadro 2 são apresentados os valores da composição granulométrica do resíduo da fibra de bambu. Para o diâmetro máximo (DM), o valor encontrado para a fibra de bambu é de 2,38 mm; sendo classificados como agregado miúdo, pois seu diâmetro está situado entre $0,075 \mathrm{~mm}$ e $4,8 \mathrm{~mm}$. O valor do módulo de finura (MF) para os agregados miúdo foi de 2,76; respectivamente para a areia sendo classificada como média, pois o módulo de finura está entre 2,4 e 3,2. Os resultados demonstram que há uma maior quantidade, em porcentagem, ou seja, de massa retida de grãos de agregado miúdo foi de $0,15 \mathrm{~mm}$.

Quadro 2. Granulometria da fibra de bambu.

\begin{tabular}{|c|c|c|c|}
\hline Peneira $(\mathrm{mm})$ & Massa Retida $(\mathrm{g})$ & Porcentagem Retida & $\begin{array}{c}\text { Porcentagem Retida } \\
\text { Acumulada }\end{array}$ \\
\hline 4,76 & 0,87 & $0,24 \%$ & $0,24 \%$ \\
\hline 2,38 & 6,35 & $1,73 \%$ & $1,97 \%$ \\
\hline 1,19 & 14,6 & $3,99 \%$ & $5,96 \%$ \\
\hline 0,59 & 59,56 & $16,26 \%$ & $22,22 \%$ \\
\hline 0,297 & 126,96 & $34,65 \%$ & $56,87 \%$ \\
\hline 0,149 & 127,08 & $34,69 \%$ & $91,56 \%$ \\
\hline 0,074 & 23,87 & $6,52 \%$ & $98,07 \%$ \\
\hline FUNDO & 7,07 & $1,93 \%$ & $100,00 \%$ \\
\hline TOTAL & 366,36 & $100,00 \%$ & 2,38 \\
\hline Diâmetro Máximo $(\mathrm{mm})$ & & 2,76 & \\
\hline Módulo de Finura & \multicolumn{3}{|}{0,76} \\
\hline Massa Específica $\left(\mathrm{g} / \mathrm{cm}^{3}\right)$ & &
\end{tabular}


Na Figura 2 são mostradas as curvas granulométricas da areia e do resíduo da fibra de bambu. As curvas da distribuição granulométrica mostram que a areia e a o resíduo da fibra de bambu é pertencente a faixa da zona ótima, pois o módulo de finura está na faixa de valores entre 2,20 e 2,90. Comparando os valores da areia com o resíduo de fibra de bambu observa-se que satisfaz a condição de substituição parcial dela quanto ao critério do diâmetro dos grãos. Segundo a NBR 7211 (2019), através da faixa de valores do agregado miúdo, observou-se que o valor do modulo de finura da areia e resíduo da fibra de bambu é classificada como areia média, pois está entre 2,40 e 3,30.

Figura 2. Curvas granulométricas-agregados miúdos.

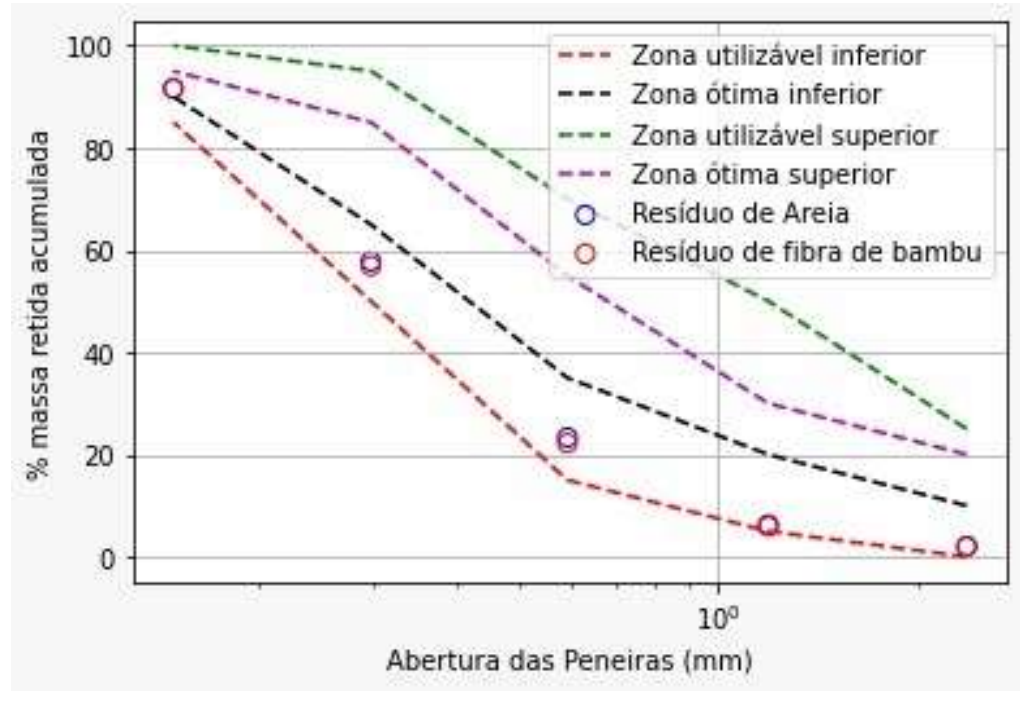

Fonte: Autores (2021).

No Quadro 3 são apresentados os valores da composição granulométrica da Brita. Na Quadro 3 observou-se que o diâmetro das partículas está incluído na faixa de brita 1 com diâmetro máximo de 19,00 mm, pois está relacionado a grandeza associada à distribuição granulométrica do agregado, correspondente à abertura de malha quadrada, em mm, à qual corresponde uma porcentagem retida acumulada igual ou imediatamente inferior a 5\%. Os resultados demonstram que há uma maior quantidade, em porcentagem, ou seja, de massa retida de grãos de resíduo de fibra de bambu na peneira com abertura de 9,52 mm. Segundo a norma ABNT 7211 (2019), a brita quase se encaixa na zona granulométrica 9,5/25 em sua classificação. 
Quadro 3. Granulometria da Brita.

\begin{tabular}{|c|c|c|c|}
\hline Peneira $(\mathbf{m m})$ & $\begin{array}{c}\text { Massa Retida } \\
\mathbf{( g )}\end{array}$ & Porcentagem Retida & $\begin{array}{c}\text { Porcentagem } \\
\text { Retida Acumulada }\end{array}$ \\
\hline 31,5 & 0,00 & $0,00 \%$ & $0,00 \%$ \\
\hline 25,4 & 0,00 & $0,00 \%$ & $0,00 \%$ \\
\hline 19,1 & 0,00 & $0,00 \%$ & $0,00 \%$ \\
\hline 12,5 & 1770,00 & $31,12 \%$ & $31,12 \%$ \\
\hline 9,52 & 2647,50 & $46,55 \%$ & $77,67 \%$ \\
\hline 4,8 & 1067,50 & $18,77 \%$ & $96,44 \%$ \\
\hline FUNDO & 202,50 & $3,56 \%$ & $100,00 \%$ \\
\hline & & $100,00 \%$ & \\
\hline TOTAL & 5687,50 & 19,0 & \\
\hline Diâmetro Máximo $(\mathrm{mm})$ & \multicolumn{3}{|c|}{2,55} \\
\hline Módulo de Finura & \multicolumn{3}{|c|}{2,81} \\
\hline Massa Específica $\left(\mathrm{g} / \mathrm{cm}^{3}\right)$ & & \\
\hline
\end{tabular}

Fonte: Autores (2021).

Na Figura 3 são apresentados os valores da resistência à compressão axial a 14 e 28 dias de cura. Através dos resultados, observou-se que a resistência a compressão não alterou os seus valores da amostra referência para a amostra com $2 \%$ aos 14 dias. Entretanto, observou-se um pequeno crescimento da resistência a compressão da amostra com $2 \%$ para a amostra com $5 \%$ com resíduo de fibra de bambu.

Figura 3. Resistência à compressão axial do concreto $\left(\mathrm{F}_{\mathrm{ck}}\right)$ a 14 e 28 dias.

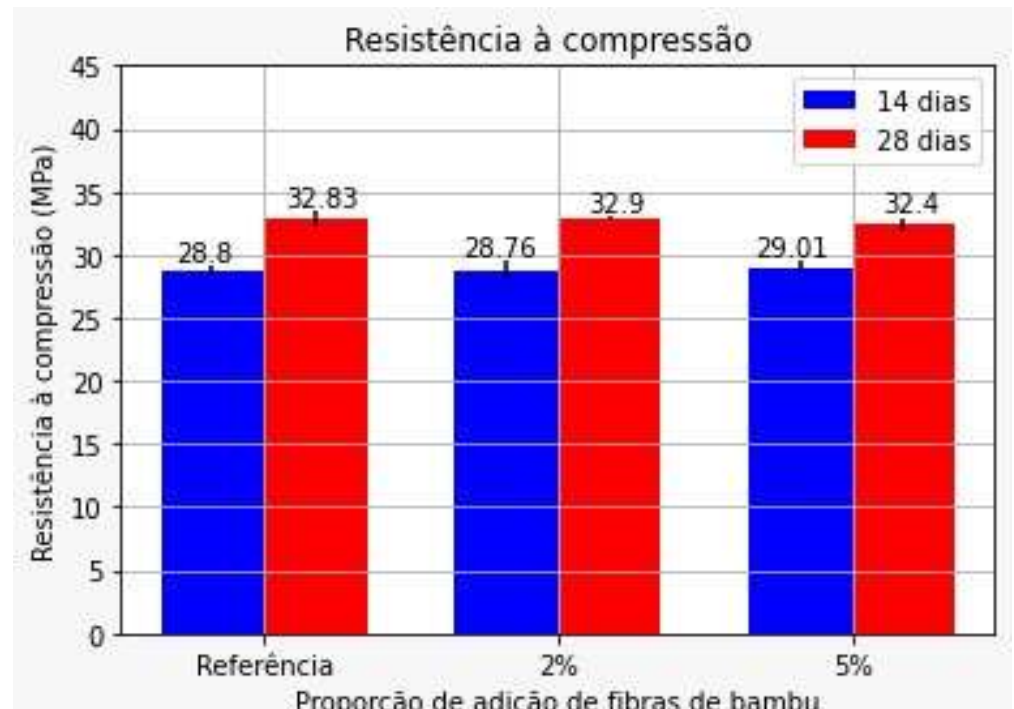

Fonte: Autores (2021).

Para os 28 dias observou-se que a resistência a compressão também não alterou seus valores da amostra referência para a amostra com 5\%. Este fato provavelmente é explicado devido a argamassa ser um material compósito, onde ao sofrer uma força de compressão, as partículas de areia e cimento tendem a criar atrito entre si e com a substituição das fibras este atrito tende a aumentar, perdendo assim a continuidade por conta da fibra de bambu, provocando assim uma menor resistência a compressão (Sandre et al., 2019). 
Também se observou um crescimento nos valores da resistência a compressão nas amostras referência a 5\% com resíduo de fibra de bambu de 14 dias para 28 dias. Ferreira, Fernandes, Cavalcante e Teixeira (2019), em sua pesquisa com o acréscimo de fibras de bambu verificou que entre as composições de $2 \%$ e $5 \%$ obtiveram um ganho da resistência a compressão de 34,04 MPa e 24,77 MPa para 28 dias. Também notou-se que para ambos o concreto referência (0\%) e o concreto de 3\% tiveram resultados satisfatórios nos testes realizados, entretanto para o concreto com $5 \%$ obteve resultados abaixo da meta proposta, estabelecido pela ABNT NBR 6118 (2014). Esses resultados indicou a possibilidade de adicionar 3\% de Cimento Portland com fibras de bambu, sem prejuízo de resistência à compressão. Paula e Nogueira (2021) investigaram três traços para o concreto convencional, um para concreto com substituição de $1 \%$ de fibra de bambu e a última com substituição de $2 \%$ de fibra de bambu, onde foram submetidos os corpos-de-prova aos testes de compressão uniaxial e notou-se que não houve uma diferença significativa nos resultados da compressão axial com a substituição de fibras.

Na Figura 4 são apresentados os valores encontrados para o módulo de elasticidade a 14 e 28 dias de cura para o concreto. Através dos resultados, observou-se que o módulo de elasticidade não alterou seus valores da amostra referência para a amostra com 5\% para a idade de 14 dias. Para os 28 dias observou-se que o módulo de elasticidade também não alterou seus valores da amostra referência para a amostra com 5\%. Também se observou um crescimento nos valores do módulo de elasticidade nas amostras referência a 5\% com resíduo de fibra de bambu de 14 dias para 28 dias. Gouveia (2014) realizou um estudo das propriedades mecânicas do concreto convencional com substituição de fibras de bambu e observou-se que os valores do módulo de elasticidade não houve variação significativa.

A inclusão de fibras no concreto tem pouca influência no módulo de elasticidade, na retração por secagem e na fluência de compressão. Entretanto, na maioria dos estudos, devido ao pequeno volume, as fibras agem simplesmente como inclusões rígidas na matriz, sem produzirem muito efeito na estabilidade dimensional do material (Coró, 2002).

Figura 4. Módulo de elasticidade do concreto a 14 e 28 dias.

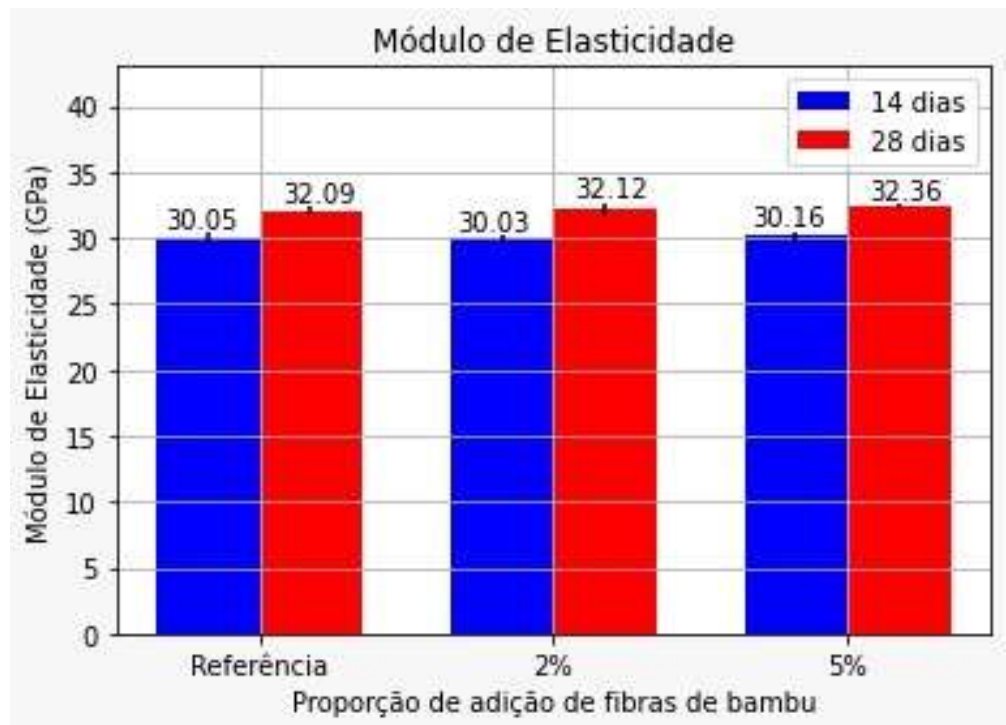

Fonte: Autores (2021).

A Figura 5 são encontrados os valores para a resistência a tração direta a 14 e 28 dias de cura para o concreto. Através dos resultados, observou-se que a resistência a tração direta não alterou seus valores da amostra referência para a amostra com 5\% para a idade de 14 dias. Para os 28 dias observou-se que os valores da resistência a tração direta também não alteraram da amostra referência para a amostra com 5\%. Também se observou um crescimento nos valores da resistência a tração direta nas amostras referência a 5\% com resíduo de fibra de bambu de 14 dias para 28 dias. 
Segundo a literatura uma das principais limitações do concreto é sua baixa resistência à tração, que é de apenas 7\% a $10 \%$ de sua resistência à compressão. Segundo esse contexto, pode ser observado, a partir dos resultados dos concretos com substituição de fibras de bambu que a resistência à tração está acima de $9 \%$ da resistência à compressão em todos os concretos produzidos quando se adicionou as fibras (Gói, 2010).

Figura 5. Resistência a tração direta a 14 e 28 dias.

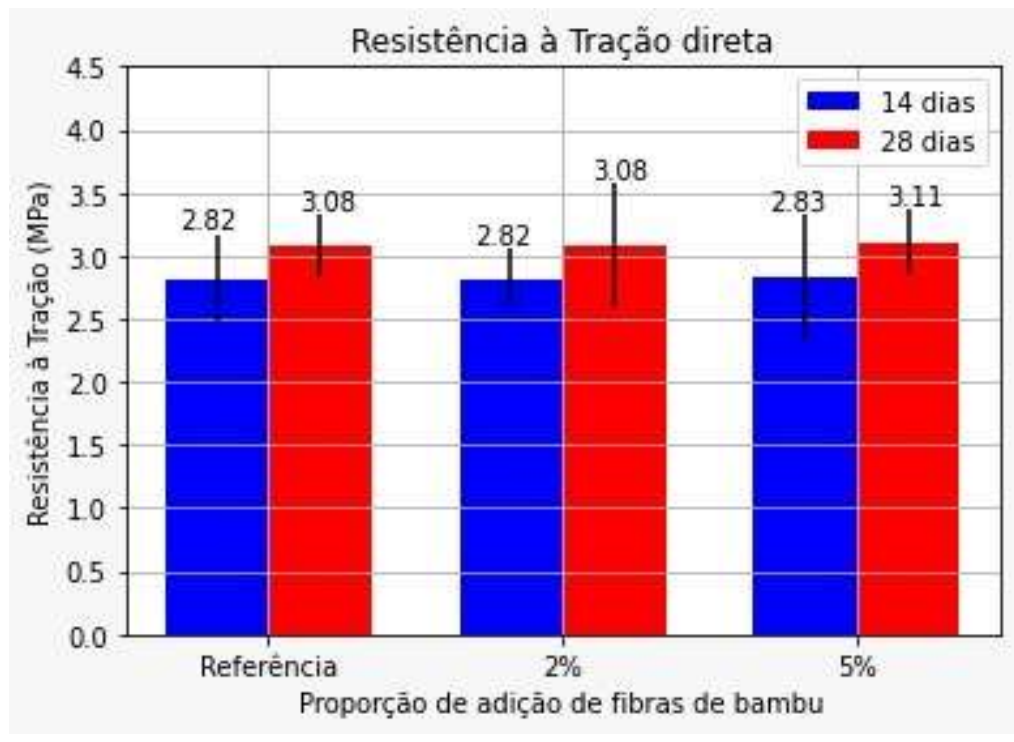

Fonte: Autores (2021).

\section{Conclusão}

O objetivo do estudo busca investigar as propriedades físicas e mecânicas da substituição da areia pela fibra de bambu sendo observado que através dos resultados, observou-se que a resistência a tração direta não alterou seus valores da amostra referência para a amostra com 5\% para a idade de 14 dias. Para os 28 dias observou-se que os valores da resistência a tração direta também não alteraram seus valores da amostra referência para a amostra com 5\%. Também se observou um crescimento nos valores da resistência a tração direta nas amostras referência a 5\% com resíduo de fibra de bambu de 14 dias para 28 dias.

Através dos resultados, observou-se que a resistência a compressão não alterou os seus valores da amostra referência para a amostra com $2 \%$ aos 14 dias. Entretanto, observou-se um pequeno crescimento da resistência a compressão da amostra com 2\% para a amostra com 5\% com resíduo de fibra de bambu. Para os 28 dias observou-se que a resistência a compressão também não alterou seus valores da amostra referência para a amostra com 5\%.

Através dos resultados, observou-se que o módulo de elasticidade não alterou seus valores da amostra referência para a amostra com 5\% para a idade de 14 dias. Para os 28 dias observou-se que o módulo de elasticidade também não alterou seus valores da amostra referência para a amostra com 5\%. Também se observou um crescimento nos valores do módulo de elasticidade nas amostras referência a 5\% com resíduo de fibra de bambu de 14 dias para 28 dias.

Para as principais sugestões de trabalhos futuros, a investigação da microestrutura do concreto com resíduo da fibra de bambu e relacioná-la com suas propriedades físicas e mecânicas, uso da Espectroscopia de Impedância Eletroquímica (EIE) para monitoramento da corrosão em concreto armado e investigação estrutural através de difração de raio x. 


\section{Referências}

ABNT 7211. (2019). Agregados para concreto - Especificação. In Agregados para concreto - Especificação.

ABNT NBR 16605. (2017). Cimento Portland e outros materiais em pó - Determinação da massa específica.

ABNT NBR 16889. (2020). Concreto - Determinação da consistência pelo abatimento do tronco de cone.

ABNT NBR 16916. (2021). Agregado miúdo - Determinação da massa específica e massa específica aparente.

ABNT NBR 16917. (2021). Agregado graúdo - Determinação da massa específica, massa específica aparente e absorção de água. In Concrete.

ABNT NBR 16972. (2021). Agregados - Determinação da massa unitária e do volume de vazios. In ABNT NBR 45:2006.

ABNT NBR 5738. (2016). Concreto - Procedimento para moldagem e cura de corpos de prova.

ABNT NBR 6118. (2014). Projeto de estruturas de concreto - Procedimento.

ABNT NBR 7212. (2021). Execução de Concreto dosado em central - Procedimento. ABNT NBR 7212:2012, 16.

ABNT NBR 8522. (2021). Concreto - Determinação dos módulos estáticos de elasticidade e de deformação à compressão.

ABNT NBR 9778. (2009). Argamassa e concreto endurecidos - Determinação da absorção de água, índice de vazios e massa específica.

Coró, A. G. (2002). Investigação das propriedades mecânicas de concretos reforçados com fibras pet. Universidade Regional do Noroeste do Estado do Rio Grande do Sul,

Dewi, S. M., Wijaya, M. N., \& Remayanti, N. C. (2017). The use of bamboo fiber in reinforced concrete beam to reduce crack. AIP Conference Proceedings, 1887(September 2017). https://doi.org/10.1063/1.5003486

Farias, M. G.; Silva, A.; Langer, R. (2007). Ecodesign e Produção Mais Limpa : inovação em Produto no APL madeira móveis. Ecodesign e Produção Mais Limpa: Inovação Em Produto No APL Madeira Móveis, 6.

Gói, F. A. P. (2010). Avaliação experimental do comportamento de concreto fluido reforçado com fibras de aço: Influência do fator de forma e da fração volumétrica das fibras nas propriedades mecânicas do concreto. Universidade Federal de Alagoas.

Ferreira, G. M., Fernandes, F. A. da S., Cavalcante, H. P., \& Teixeira, M. B. (2019). Characterization of the Mechanical Properties of Concrete with Addition of Bamboo Fiber - Porto Nacional/TO. International Journal of Advanced Engineering Research and Science, 6(11), 209-216. https://doi.org/10.22161/ijaers.611.32

Guimarães, M., Novack, K. M., Botaro, V. R., De Paula Protásio, T., \& Couto, A. M. (2013). Caracterização físico-química de fibra e polpas de bambusa vulgaris schrad para utilização em compósitos poliméricos. Revista Latinoamericana de Metalurgia y Materiales, $33(1), 33-42$.

Kumarasamy, K., Shyamala, G., Gebreyowhanse, H., \& Kumarasamy. (2020). Strength Properties of Bamboo Fiber Reinforced Concrete. IOP Conference Series: Materials Science and Engineering, 981(3). https://doi.org/10.1088/1757-899X/981/3/032063

Leonardo Lúcio de Araújo Gouveia; Ricardo Luiz Perez Teixeira; Carlos Augusto de Souza Oliveira; Bruno Henrique Moreira Ferreira; Sheron Stephany Tavares; Carla Regina Ferreira. (2014). Estudo Comparativo Das Propriedades Mecânicas Do. 792-801.

Marrero, R. E., Soto, H. L., Benitez, F. R., Medina, C., \& Suarez, O. M. (2017). Study of high-strength concrete reinforced with bamboo fibers. Advanced Materials - TechConnect Briefs 2017, 2, 301-304.

Monteiro, P., \& Mehta, P. (2006). Concrete: Microstructure, Properties and Materials. In McGraw-Hill.

Mota, L. A. C. . A. V. (2007). Caracterização de Fibras Curtas Empregadas na Construção Civil Leila Aparecida de Castro Motta.

NBR 5739. (2018). Concreto - Ensaio de compressao de corpos-de-prova cilindricos.pdf.

NBR NM 248. (2003). NBR NM 248: Agregados - Determinação da composição granulométrica. In Test.

Paula, A., \& Nogueira, L. (2021). Analysis of Concrete Strength with Addition of Bamboo Fiber. 3, 80-90.

Sandre, D. S. de, Bianchi, G., Trentin, T. F. da S., \& Cavazzana, T. L. (2019). Viabilidade para Implementação de Fibras de Bambu em Argamassas. Revista Científica ANAP Brasil, 12(24), 86-100. https://doi.org/10.17271/19843240122420191985

Santi, T. (2015). Bambu para. Revista O Papel, April, 23-34. 